BMJ Nutrition,

Prevention \& Health

\title{
Nutrition education in medical school: the case of international medical students in China
}

\author{
William Kwame Amakye, ${ }^{1}$ Sladana Bozovic, ${ }^{1}$ Arafat Faraque, ${ }^{1}$ Maojin Yao, ${ }^{2}$ \\ Jiaoyan Ren (1D ${ }^{1}$
}

To cite: Amakye WK, Bozovic S, Faraque A, et al. Nutrition education in medical school: the case of international medical students in China. BMJ Nutrition, Prevention \& Health 2020;3:e000117. doi:10.1136/ bmjnph-2020-000117

${ }^{1}$ School of Food Science and Engineering, South China University of Technology, Guangzhou, China

${ }^{2}$ Guangzhou Institute of Respiratory Disease and China State Key Laboratory of Respiratory Disease, First Affiliated Hospital of Guangzhou Medical University, Guangzhou, China

\section{Correspondence to} Dr Jiaoyan Ren, School of Food Science and Engineering, South China University of Technology, Guangzhou 510640, China; jyren@scut.edu.cn

Received 7 June 2020 Revised 20 0ctober 2020 Accepted 10 November 2020 Published Online First 1 December 2020

Check for updates

(C) Author(s) (or their employer(s)) 2020. Re-use permitted under CC BY-NC. No commercial re-use. See rights and permissions. Published by BMJ.

\section{ABSTRACT}

Objective To assess the knowledge on country-specific nutrition situation, perceptions of the nutrition curricula and factors influencing capacity to offer nutrition guidance among medical students studying internationally in China compared with their home-country counterparts.

Design Cross-sectional study.

Settings China, Ghana, India and Montenegro.

Participants International medical students in China and medical students studying in their home countries of Ghana, India and Montenegro.

Main measure An online semistructured questionnaire was administered using WeChat for international students and Microsoft Forms for home-country medical students to assess students' perceived knowledge and significance of nutrition, knowledge of country-specific nutrition situation, perceptions of the nutrition curricula and perceived capacity to offer nutrition counselling.

Result In all, 190 medical students responded to the survey: 110 international students studying in China and 80 home-country students from Ghana (40), India (20) and Montenegro (20). Home-country students rated the importance of nutrition in health and disease development higher than international students $(p<0.05)$. International students reported not having any specific nutrition courses while home-country students had nutrition courses as part of their curriculum. Only $8.2 \%$ of international students and $13.8 \%$ of home-country students were able to correctly mention any specific national nutrition guidelines of their home countries. Home-country students were more likely to provide correct nutrition recommendations for infants $\left(\chi^{2}(3)=26.349 ; p=0.001\right)$, pregnancy $\left(\chi^{2}(3)=9.793\right.$; $p=0.007)$, lactating mothers $\left(\chi^{2}(3)=9.112 ; p=0.011\right)$, diabetes $\left(\chi^{2}(3)=13.619 ; p=0.001\right)$, hypertension $\left(\chi^{2}(3)=12.022 ; p=0.002\right)$, overweight/obesity $\left(\chi^{2}(3)=8.896\right.$; $\mathrm{p}=0.012)$ and undernutrition $\left(\chi^{2}(3)=7.670 ; p=0.022\right)$ compared with international students. Practical nutrition courses, hours of nutrition education and how often students were asked nutrition-related questions tended to affect and predict the adequacy of nutrition education received and the perceived confidence for nutrition counselling.

Conclusion International medical students in China are less familiar with the nutrition context in their respective home countries compared with their homecountry counterparts. Medical schools in China that train significant numbers of international students need to support these students to become familiar with their respective countries' nutrition contexts.

\section{What this paper adds}

Knowledge on respective home-country nutrition situation of international medical students studying in China were assessed.

- Factors influencing capacity of medical students to offer nutrition guidance were explored.

- International medical students in China were less familiar with the nutrition context in their respective home countries.

\section{INTRODUCTION}

Nutrition is perhaps the single most important determining factor for a strong immune system. ${ }^{1}$ Indeed, the aetiology, progression and/or management of diseases such as anaemia, diabetes, hypertension, cancer, hypercholesterolaemia, obesity and many other chronic diseases have been linked to nutrition. ${ }^{2}$ Experts have suggested a greater role of food and nutrition in the prevention of COVID-19 and as a potential first-line treatment option. ${ }^{3}$ Besides, research findings suggest that at least $10 \%$ of adults visiting hospitals as well as one-third of all admissions at home care and hospitals may need some form of nutrition care and support. ${ }^{4}$

Obesity-related illnesses cost the UK $£ 6.1$ billion in $2014-2015^{5}$ and diabetes costs the US $\$ 245$ billion per year. ${ }^{6}$ According to the WHO, around $45 \%$ of mortality in children under 5 years is linked to undernutrition. ${ }^{7}$ To reverse this trend, greater attention is required to be paid to nutrition services. Key to enhancing nutrition is the human resource capacity to deliver appropriate and timely nutrition education and services and to educate the population about the impact of nutrition on human health. Study findings demonstrate that participants who received different duration of nutrition education were able to make significant changes to their nutrition which resulted in improvement in both performance ${ }^{8}$ and markers 
of cardiovascular health. ${ }^{9}$ These findings revealed that appropriate nutrition education is important in both disease prevention and enhanced sports performance among adolescent athletes. This, however, requires that practitioners across the healthcare delivery system themselves be equipped with relevant knowledge and understanding of the role of nutrition in health, disease management and human development.

In low and middle-income countries where nutritionists and dieticians are less integrated into mainstream healthcare delivery, medical doctors are faced with an even more urgent task of delivering appropriate nutrition advice and services to clients. Even though research findings showed that the general public regards highly the advice, including nutrition advice, from medical doctors, ${ }^{10}$ studies have revealed inadequacies in the training of medical doctors in nutrition. ${ }^{11}{ }^{12}$ Importantly, nutrition and nutrition needs may differ from country to country or on a regional basis. For example, while developed countries are still confronted with the double burden of nutrition (overweight and obesity and micronutrient deficiencies), ${ }^{13}$ underdeveloped and low and middle-income countries and regions are grappling with the triple burden of nutrition (overweight and obesity, undernutrition and micronutrient deficiencies). ${ }^{14}$ Therefore, the nutrition knowledge needs of doctors may differ based on local conditions. In this regard, it is feared that there could be a significant gap in knowledge and ability to manage nutrition-related cases between medical doctors who study outside of their home countries and those who study in their home countries.

The Chinese government through many programmes including the 'One belt One Road' initiative has provided opportunities and scholarships for the training of medical students from many low and middle-income countries in Chinese medical schools in an attempt to help these countries to meet their human resource capacities in the health sector. Using a sample from this cohort of international medical students, we aimed to assess the differences in nutrition knowledge and factors influencing the capacity of international medical students in China to offer nutrition guidance compared with their homecountry counterparts.

\section{METHODS}

\section{Study design}

The study took the form of a cross-sectional study. Participants were medical students either studying internationally in China (international students) or studying in their home country (home-country).

\section{Participant recruitment}

Participants were recruited through key contact persons in various medical schools. Due to the COVID-19 pandemic with its associated lockdown and need for social distancing during the survey period, an online recruitment exercise was initiated. Online questionnaires were forwarded to various class and school social media platforms through these key contact persons with clear instructions on who qualifies to fill the questionnaire for interested students to respond. International students from a total of eight schools, including the Southern Medical University (Guangzhou, Guangdong Province), Sun Yat-sen University (Guangzhou, Guangdong Province), Jiamusi University (Jiamusi, Heilongjiang Province), Jinan University (Guangzhou, Guangdong Province), Dalian Medical University (Dalian, Liaoning Province), Gannan Medical University (Ganzhou City, Jiangxi Province), Ningbo University (Zhejiang Province) and Shenyang Medical College (Shenyang, Liaoning Province), were included in this study. For inclusion, a participant had to be a current medical student either studying internationally in China for the international students group or studying in their home country. Respondents were made aware the questionnaire was strictly for research purposes and the structure of the questionnaire did not reveal the respondent's identity. Responding to the questionnaire was regarded as informed consent and no incentives were given for responding to the questionnaire.

\section{Data collection}

Data were collected solely through the administration of a semistructured questionnaire (online supplementary file 1) modified from the Nutritank Medical Students Survey reported by Macaninch et al. ${ }^{15}$ The rationale for modifications to the questionnaire was mainly to capture enough and precise information relevant to the goal of our survey. Consequently, the changes were mainly in the form of additions that were not in the original questionnaire but were necessary given the focus of our survey. For example, the original set of the questionnaire did not include questions accessing students' knowledge on nutrition policies in their home countries and did not assess knowledge on specific disease conditions so we needed to add these to suit the aims of the current study. The questionnaire for participants studying in China was developed and distributed through the popular WeChat app by Tencent while students studying in their home countries were reached with the questionnaire developed with Microsoft Forms. The links for the respective questions were sent through the key contacts into the school/ class groups to invite interested participants to respond. The questionnaire included portions such as basic information (age, nationality, the medium of teaching instruction and current year of study), knowledge on country-specific nutrition situation, nutrition-related curriculum content, perceived nutrition knowledge and personal perspectives. The survey was first conducted for international students in China from 1 to 7 May 2020. Ghana and India were chosen for the selection of homecountry students because they had the highest numbers of students among the international student respondents. Montenegro was selected for its similarities in terms of socioeconomic characteristics (low and middle-income country) but geographically apart from the other chosen 
countries. The survey for the home-country students was conducted from 12 to 19 May 2020.

\section{Data analysis}

The basic characteristics of participants were analysed as one sample and then also compared between groups and expressed as means and SDs for continuous variables and percentages for categorical variables. Differences between groups were assessed using an independent samples t-test. Data were then transformed into categorical data by frequency count and analysed using Pearson $\chi^{2}$ test for the differences between any two groups. In all analyses, a $\mathrm{p}$ value $<0.05$ was considered significant. All analyses were carried out using IBM SPSS Statistics V.21.

\section{RESULTS}

\section{Basic characteristics of participants}

Participants' basic characteristics are presented in table 1. In all, a total of 190 students responded to the survey questionnaire. Out of these, 110 were foreign students studying in China, and 80 were studying in their home countries made of Ghana (40), India $(20)^{16}$ and Montenegro (20). The mean age of participants in this study was $23.6 \pm 4.8$ years. For the international students mean age was 23.4 \pm 5.4 years, and 24.0 \pm 3.6 years for homecountry students $(\mathrm{p}=0.394)$. Compared with the international students, home-country students in Ghana were older $(25.4 \pm 3.4, \mathrm{p}<0.032)$ and students from Montenegro were younger $(20.6 \pm 1.6, \mathrm{p}<0.026)$. Overall, $20.50 \%$ of the participants were in their first year of medical studies, with $11.6 \%, 12.1 \%, 9.5 \%$ and $46.3 \%$ in their second, third, fourth and fifth years or beyond in medical school, respectively. Moreover, $15.8 \%$ and $21.6 \%$ of international students were in first year or at least fifth year compared with $4.70 \%$ and $24.80 \%$, respectively, among homecountry students $(\mathrm{p}<0.001)$. The majority of respondents in Ghana $(80.0 \%, \mathrm{p}<0.001)$ and India $(60.0 \%, \mathrm{p}<0.025)$ were in the fifth year or above. Compared with the international students group, a larger portion of participants from Montenegro were either in their first year $(35.0 \%)$ or second year $(25.0 \%)(\mathrm{p}<0.045)$.

\section{Perceived significance of nutrition}

Participants' self-perceived significance of nutrition is presented in figure 1. The overwhelming majority of participants $(77.4 \%)$ strongly agreed that nutrition is significant in health and $42.1 \%$ and $38.9 \%$, respectively, agreed or strongly agreed that nutrition is significant in disease development. 94.2\% accepted that nutrition has a significant role in the management of disease conditions. When the data were split into groups, we found that home-country students tended to agree more to the role of nutrition in health $\left(\chi^{2}(3)=11.552 ; \mathrm{p}=0.009\right)$ and disease development $\left(\chi^{2}(3)=10.372 ; \mathrm{p}=0.016\right)$ compared with international students. No differences existed between the groups or subgroups on the perceived significance of nutrition in disease management. Subgroup analysis showed home-country students in Ghana strongly agreed to a significant role of nutrition in health $\left(\chi^{2}(3)=10.600 ; \mathrm{p}=0.014\right)$ and disease development $\left(\chi^{2}(3)=12.922 ; \mathrm{p}=0.005\right)$ compared with the international students. Similar results were obtained for homecountry students in India on the significance of nutrition in disease development $\left(\chi^{2}(3)=10.486 ; \mathrm{p}=0.015\right)$ but not in health $\left(\chi^{2}(3)=3.785 ; \mathrm{p}=0.151\right)$; and home-country Montenegro students on the significance of nutrition in health $\left(\chi^{2}(3)=7.139 ; p=0.028\right)$ but not in disease development $\left(\chi^{2}(3)=4.199 ; p=0.241\right)$ compared with the international students. Overall, medical students rated very highly ( 4 and above out of 5 ) the significance of nutrition in medical school. However, group analysis showed that home-country students rated higher the significance of nutrition in medical school compared with international students. Further analysis revealed that the differences were between the Montenegro $\left(\chi^{2}(2)=40.925 ; \mathrm{p}<0.001\right)$ but not the Ghana $\left(\chi^{2}(2)=1.581 ; \mathrm{p}=0.0454\right)$ and India $\left(\chi^{2}(2)=3.041 ; 0.219\right)$ subgroups compared with the international students group.

\section{Knowledge of country-specific nutrition situation}

The majority of participants agreed that nutrition is considered very important $(54,31.8 \%)$ or important $(75$, $44.1 \%$ ) in their respective home countries (table 2). No differences were found between international students and home-country students or home-country subgroups $(\mathrm{p}>0.05)$. However, only $70(36.8 \%)$ participants were aware of the existence of nutrition policies in their home countries though most could list prevalent nutrition diseases in their home countries (online supplemental table 1). Surprisingly, more international students (45, $40.9 \%$ ) were aware of the existence of national nutrition policies in their respective home countries compared with the home-country students $(25,31.3 \%):\left(\chi^{2^{3}}(3)=30.309\right.$; $\mathrm{p}=0.001)$. Of note, only $20(10.5 \%)$ of all participants were able to correctly mention any specific nutrition policy in their respective home countries. No differences were found between the international students and home-country students but subgroup analysis showed that home-country Ghanaian students $(8,20.0 \%)$ could name more $\left(\chi^{2^{2}}(2)=4.077 ; \mathrm{p}=0.046\right)$ compared with the international students $(9,8.2 \%)$.

\section{Nutrition education in the medical school}

Participants' assessment of the nutrition education received at the medical school is presented in table 3 . From the results, 82 participants $(43.2 \%)$ had received 2 or fewer hours (0-2 hours) of nutrition and nutritionrelated education during the last academic year while 62 $(32.6 \%)$ and $46(24.2 \%)$ had received 3-6 hours and 7 or more hours, respectively. There were no differences in the number of nutrition and nutrition-related teaching hours received between the international and homecountry students as well as the subgroups of the homecountry students. Furthermore, $17.4 \%$ of respondents said the nutrition education in their schools was elective, 


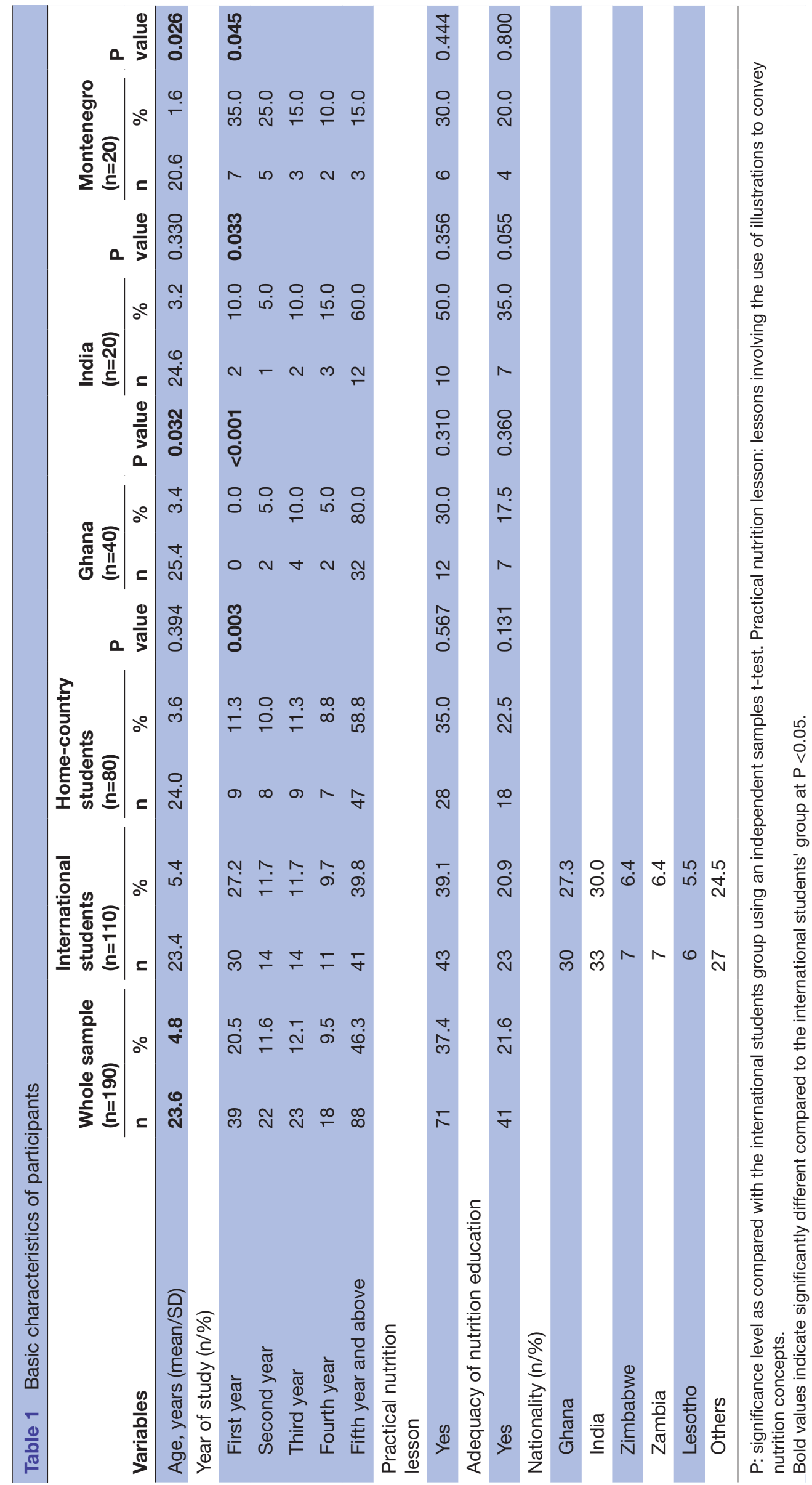

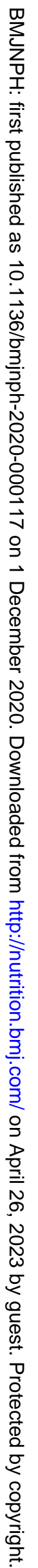


A

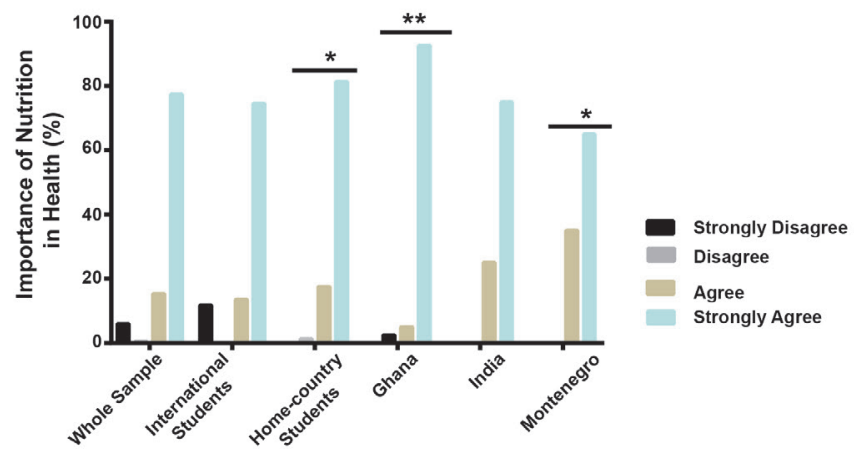

C

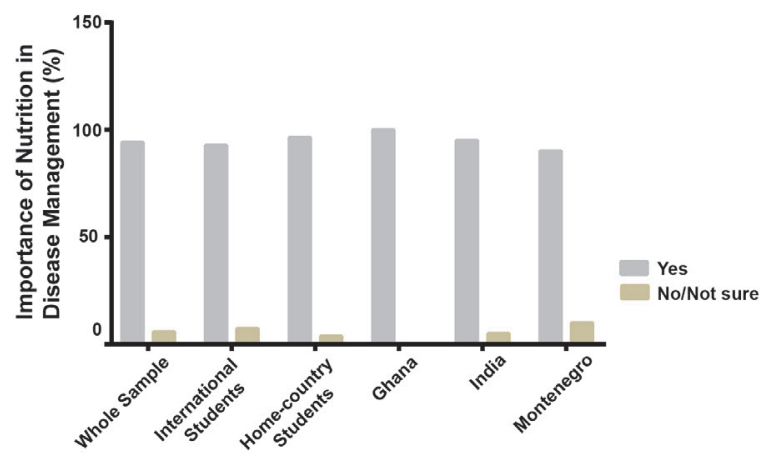

B

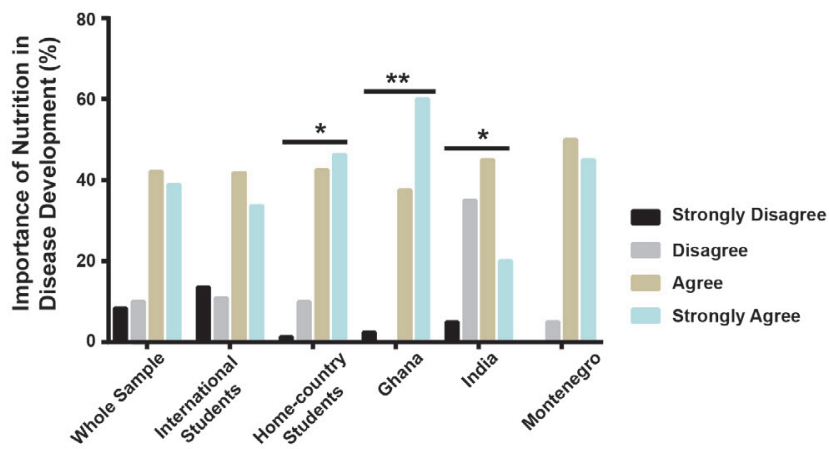

D

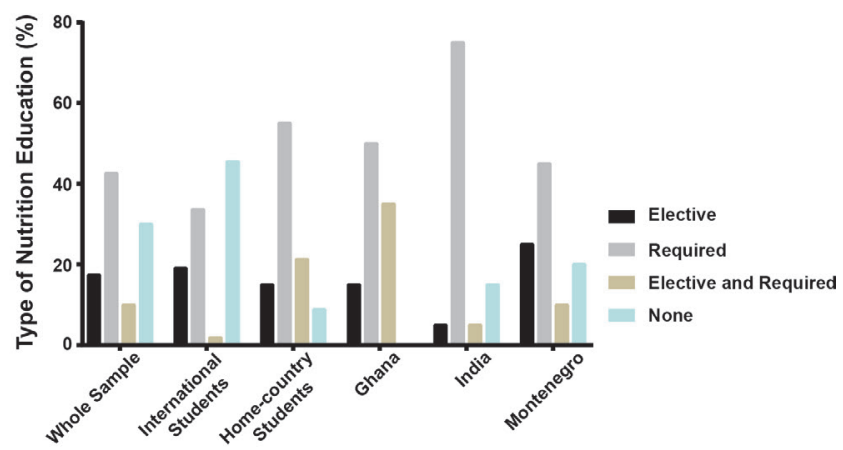

Figure 1

Figure 1 The perceived significance of nutrition. (A) Importance of nutrition in health. (B) Importance of nutrition in the development of disease. (C) Importance of nutrition in the management of diseases. (D) Self-reported type of nutrition education received in medical school. ${ }^{*} \mathrm{P}<0.05 ;{ }^{* *} \mathrm{p}<0.01$.

$42.6 \%$ as a required course while $30.0 \%$ of respondents had no nutrition education. In the group analysis, it was found that nutrition education among home-country students tended to be as a required course $(55.0 \%)$ while international students $(45.5 \%)$ tended to have none at all $\left(\chi^{2^{3}}(3)=43.693 ; p=0.001\right)$. Besides, only $21.6 \%$ of all participants agreed that the nutrition education received at their respective medical schools was adequate for their future needs as doctors with $48.9 \%$ disagreeing and $29.5 \%$ not being sure. There were no significant differences between groups and subgroups in terms of student-perceived adequacy of nutrition education in their respective schools. Related to this question, $40.0 \%$ of all students were not sure of their readiness to offer nutrition advice on the nutrition-related diseases prevalent in their respective home countries. Consequently, the vast majority of participants $(176,92.6 \%)$ made up of 102 international and 74 home-country students $(\mathrm{p}>0.05)$ said they would welcome additional nutrition education.

\section{Knowledge on nutrition management of disease conditions}

Participants' ability to give correct nutrition recommendation for selected conditions is presented in table 4 . Surprisingly, less than $50 \%$ of students could give correct and specific recommendations in each case. Comparison between international and home-country students showed significant differences in their ability to give correct responses. Only $25.5 \%$ of international students and $50 \%$ of home-country students were able to give correct nutrition recommendation for infants between the ages of 0 and 6 months $\left(\chi^{2^{3}}(3)=26.349 ; \mathrm{p}=0.001\right)$. Similar results were obtained for pregnancy $\left(\chi^{2^{3}}(3)=9.793 ; \mathrm{p}=0.007\right)$, lactating mothers $\left(\chi^{2^{3}}(3)=9.112 ; \mathrm{p}=0.011\right)$, diabetes $\left(\chi^{2^{3}}(3)=13.619 ; \mathrm{p}=0.001\right)$, hypertension $\left(\chi^{2^{3}}(3)=12.022\right.$; $\mathrm{p}=0.002)$, overweight/obesity $\left(\chi^{2^{3}}(3)=8.896 ; \mathrm{p}=0.012\right)$ and undernutrition $\left(\chi^{2^{3}}(3)=7.670 ; \mathrm{p}=0.022\right)$ with the home-country student group scoring higher in all cases.

\section{Relationship analysis}

Analysis of factors associated with the adequacy of nutrition education and students' perceived confidence level to offer nutrition advice is presented in table 5. The results showed that students who had some form of practical nutrition lessons perceived that the nutrition education provided was adequate $\left(\chi^{2}(2)=12.807 ; \mathrm{p}=0.002\right)$. However, the observed effect was only significant among home-country students $\left(\chi^{2}(2)=7.599 ; \mathrm{p}=0.022\right)$ and the trend among the international students did not reach statistical significance $\left(\chi^{2}(2)=7.793 ; p=0.055\right)$. Furthermore, those who had some form of practical nutrition lessons were more likely to be confident in giving nutrition advice compared with those who had no practical 


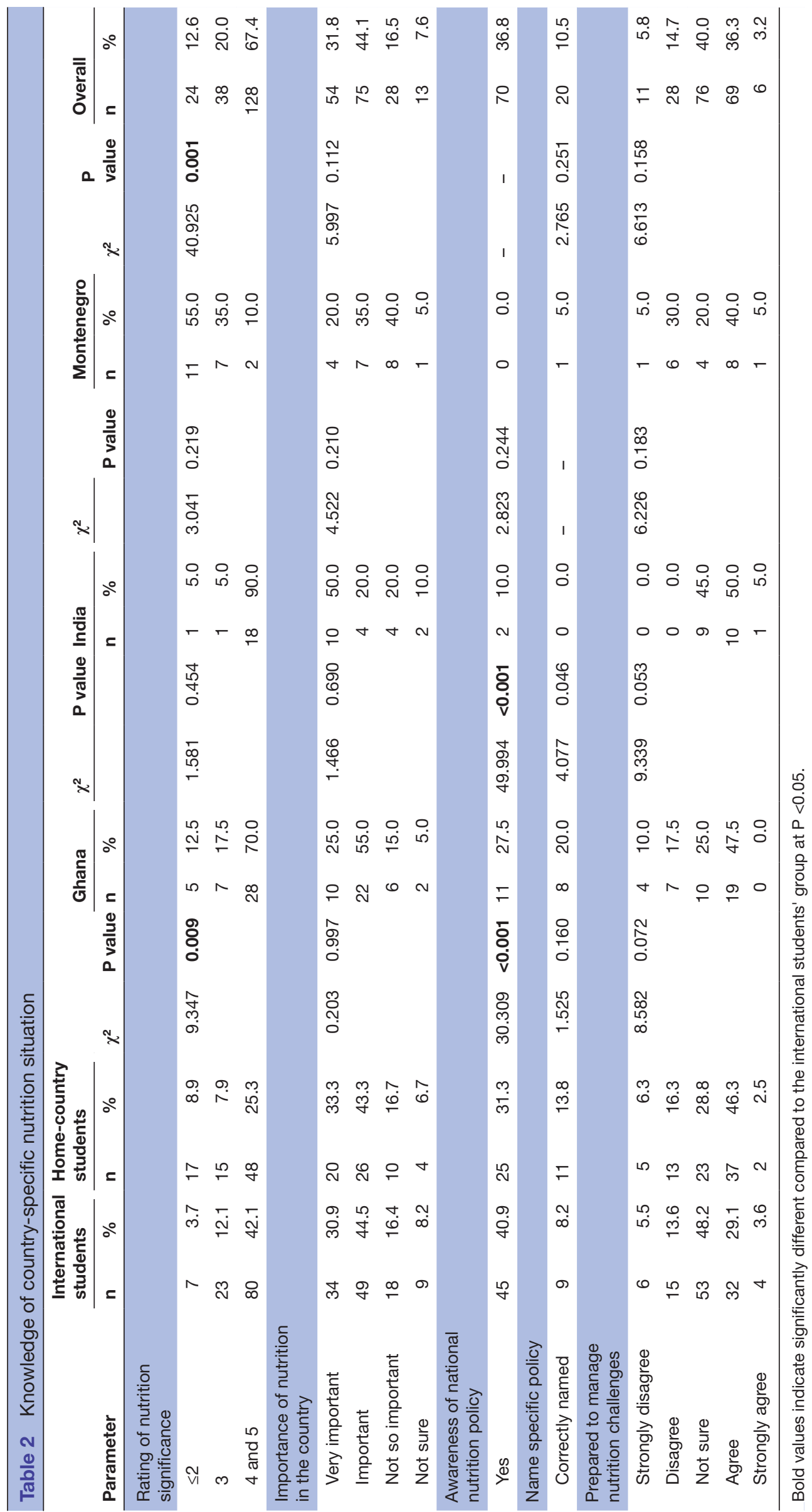




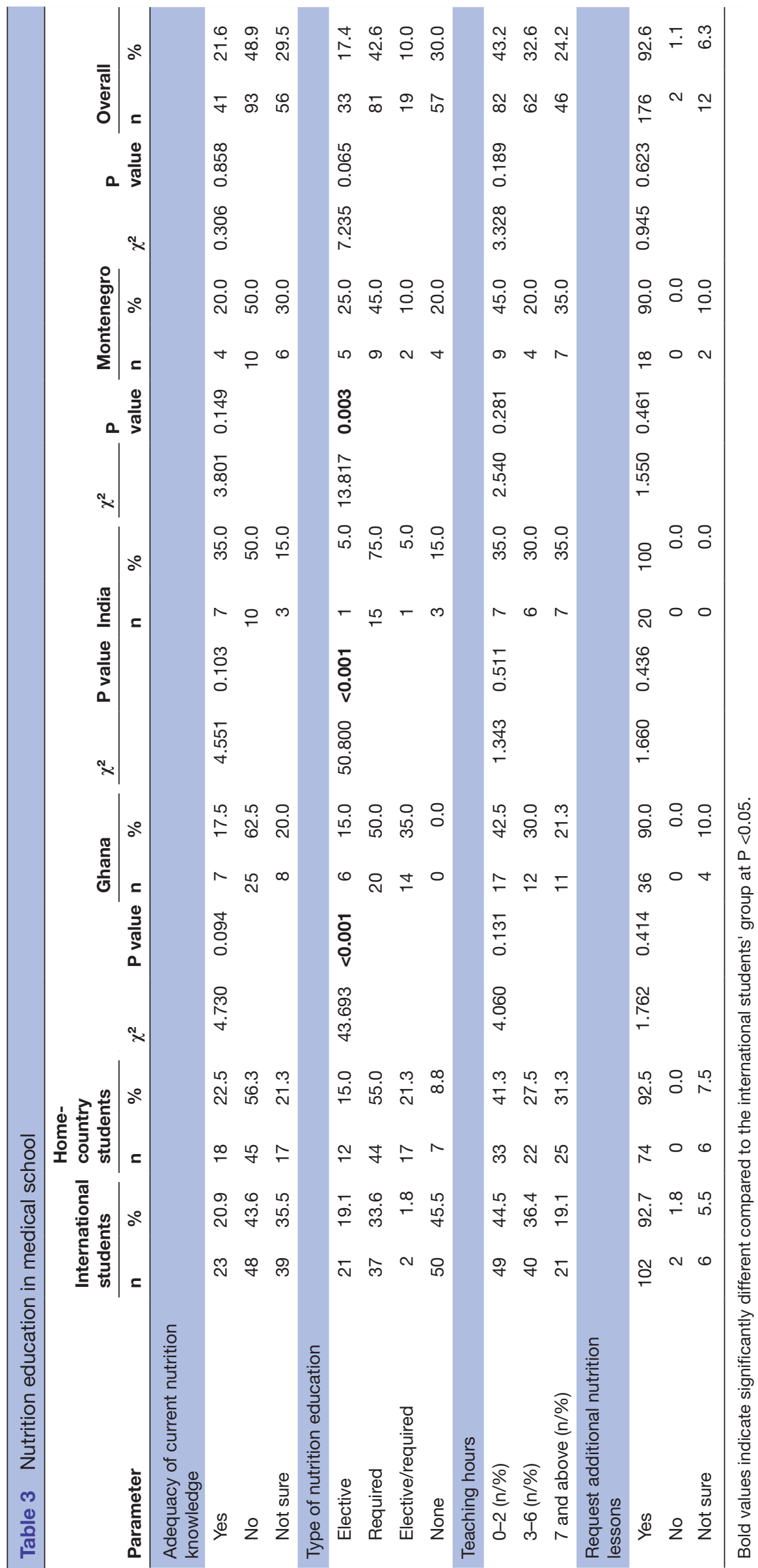




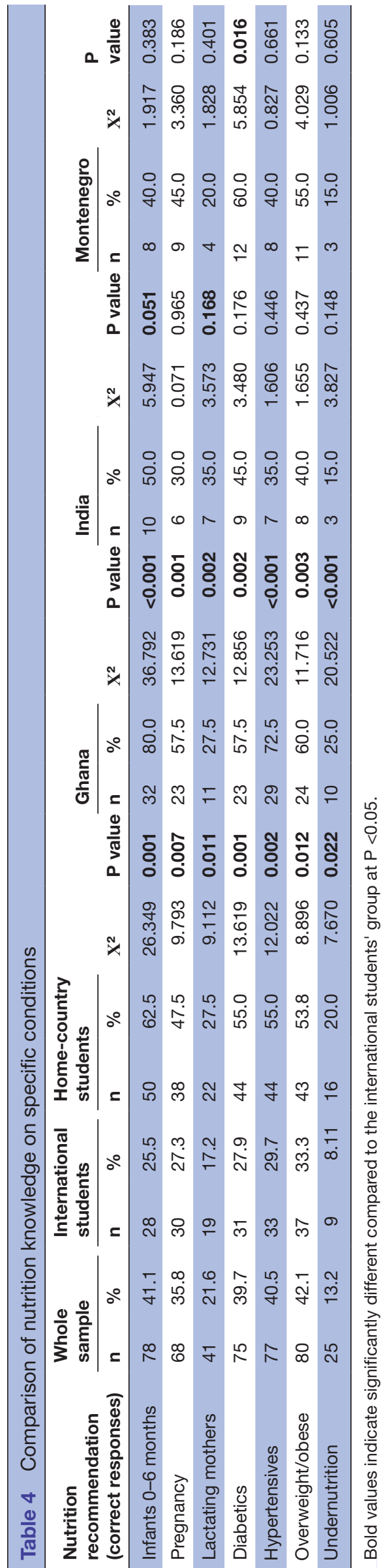

nutrition lessons $\left(\chi^{2}(4)=16.556 ; \mathrm{p}=0.002\right)$ in their schools although the nature of the practical lesson was not assessed in this study. The observed predictive effect was only significant among home-country students. Moreover, students who were asked nutrition-related questions, very often or often, felt more confident in their ability to give nutrition guidance compared with those who were rarely or never asked questions $\left(\chi^{2}(4)=15.915\right.$; $\mathrm{p}=0.003$ ). This relationship was not statistically significant when the data were analysed by groups. Furthermore, we found that students who received 5 or more hours teaching in nutrition $(25,32.9 \%)$ in the last academic year felt more adequate with their current level of knowledge in nutrition $\left(\chi^{2}(2)=16.897 ; \mathrm{p}<0.001\right)$ compared with those who received 4 or less teaching hours $(16,14.0 \%)$. This was consistent with the group analysis in the international students group but not among the home-country students. However, receiving more teaching hours on nutrition did not translate into differences in the selfperceived confidence to provide nutrition guidance.

\section{Participants' perspective on improving nutrition education in} medical schools

The overwhelming majority of students $(92 \%)$ requested more nutrition education be included in the medical curricula. When asked how additional nutrition education could be incorporated into their schools' curricula, the majority suggested the use of workshops and demonstrations on specific nutrition topics and additional lectures or integration into existing nutrition-related topics and disease conditions (online supplemental figure 1A). The vast majority of participants perceived that the biggest challenge to the clinical implementation of nutrition was lack of awareness on nutrition issues, followed by lack of interest, inadequate human resource capacity and insufficient time (online supplemental figure 1B).

\section{DISCUSSION}

The importance of nutrition in health to all sectors of society can no longer be underestimated. ${ }^{2}$ Globalisation has contributed to increasing numbers of professionals including medical students being trained outside their home countries, although they ultimately return there to practise their profession. In the current study, the nutrition knowledge and factors influencing the capacity to offer nutrition advice among medical students studying internationally in China compared with their homecountry counterparts were assessed. The results showed that home-country students rated more highly the significance of nutrition in health and disease development and had greater self-perceived confidence to provide appropriate nutrition advice for specific conditions and disease states compared with internationally trained students. The adequacy of nutrition education received at the medical school and the level of confidence in providing nutrition advice to patients correlated with factors including the practical nutrition education received, how 


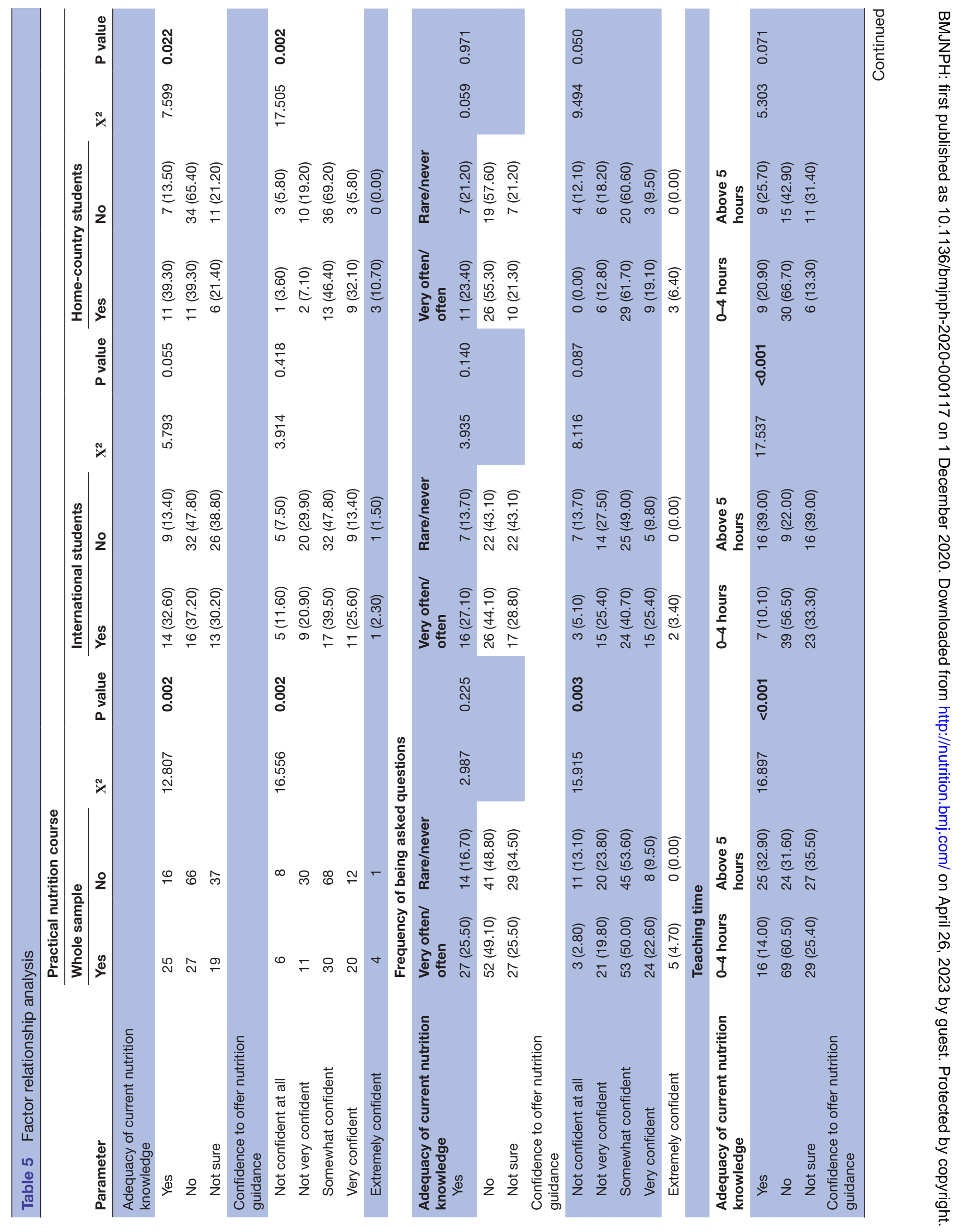


often students are asked nutrition-related questions and the hours of teaching in nutrition received. To the best of our knowledge, this is the first study to assess the nutrition knowledge and perceptions of the nutrition curricula of international medical students in China. Another novelty is the fact that participants were from different countries and continents.

Many professionals are increasingly aware of the significance of nutrition in health as is the general public. Previous studies have suggested that medical students gave high ratings for the role of nutrition in health and disease. ${ }^{17}$ This is consistent with our findings which showed that the overwhelming majority agreed that nutrition is very significant in health, disease development and disease management. Although the majority of students perceived that nutrition is considered as either important or very important in their respective home countries, a larger proportion seems to know little about specific nutrition policies in their home countries irrespective of whether they were international students or home-country students. Different countries and regions are faced with different nutritional needs and so national nutrition policies may differ. ${ }^{18}$ The ability to offer appropriate nutrition advice could be based partly on the available national nutrition guidelines ${ }^{19}$ even though there are globally accepted standards. For instance, in Ghana, the national nutrition policy ${ }^{20}$ states that households must consume iodine fortified salt (iodised salt) as a means of fighting iodine deficiency which is very prevalent in the country and this could be different in other countries. The lack of awareness of such national policies might affect the confidence and ability of professionals to offer the appropriate advice and services in the Ghanaian context.

In this study, the majority of participants recognised nutrition as essential to the medical profession, health and disease but this did not reflect in students' knowledge on the nutrition management of specific conditions including pregnancy, lactation, infant nutrition, diabetes, hypertension, obesity and undernutrition. This clearly demonstrates the disconnect between medical students' self-perceived nutrition knowledge and its application in practice. In the present study, less than $50 \%$ of all participants were able to provide a correct response for the nutrition management of pregnancy, lactation, infant (0-6 months), diabetes, hypertension, obesity and undernutrition. Homecountry students had more correct responses in each case compared with international students and much of this difference was found in the Ghana subgroup compared with the India and Montenegro subgroups. The observed difference might be attributed to the fact that more than $58 \%$ (and $80 \%$ of the Ghana cohort) of the home-country students were in the fifth year or above. This suggests that they were in the clinical or advanced stage of their studies. Such students might have greater exposure to these conditions and have gathered some knowledge and practical 
experiences. Consequently, home-country students felt more confident in their ability to offer nutrition counselling compared with international students. In a study of preclinical osteopathic medical students, Hargrove et al found that $50.6 \%$ of all participants did not obtain the pass mark in a nutrition knowledge questionnaire. ${ }^{16}$ Research findings on the perceived confidence of medical students to offer nutrition advice are not consistent. ${ }^{21-26}$

The adequacy of undergraduate medical nutrition education has long been a concern. ${ }^{23}{ }^{27}$ In the current study, we found that the adequacy of nutrition education received and the perceived confidence level of students to provide nutrition advice to patients were affected by factors including whether or not students received some form of practical nutrition training, the number of teaching hours and frequency of being asked nutrition-related questions by others. Students who received some form of practical nutrition course had perceived greater confidence in the adequacy of their nutrition knowledge and ability to counsel patients. This was consistent in the home-country group but not among the international students cohort. Practical nutrition education may reflect the application of nutrition science to clinical practice and therefore be confidence boosting. ${ }^{21}$ The reason for the non-significance observed in the international students cohort might be due to the very low number of international students who received any practical nutrition course, implying that a larger sample size might be needed to detect any potential differences. Students who were frequently asked questions related to nutrition felt more confident in their ability to offer nutrition counselling but not the adequacy of the nutrition education they have received. It is conceivable that when students are frequently asked questions, it drives them to research on the areas of questioning and this could boost their confidence over time. In addition, students who received more teaching hours in nutrition felt more adequate in what has been offered but teaching time did not correspond with confidence level for counselling. Research suggests that current nutrition education is often not translated into practice unless it is reinforced through daily patient care. ${ }^{28}$ This suggests that it is about the hours of nutrition education and clinical experience. It has been reported that there are no benchmarks for adequate nutrition education in many medical schools ${ }^{29}$; however, the findings from the research suggest that students who received some form of practical nutrition course, and not necessarily the number of hours of teaching in nutrition, had greater perceived confidence in their ability to offer nutrition counselling. Much of medical training is offered as a practical apprenticeship; as such clinical nutrition practice might be improved among students with participatory integrated nutrition curriculum. ${ }^{1521}$ This suggests that medical students would pick up courses more when it is delivered in a more practical manner. This was also evident in the suggestions by students for improving the nutrition content of the curricula which have also been reported in other studies.

\section{Proposed intervention plan}

To help address the root causes of the knowledge gaps identified by this survey, we propose the following:

First, in line with students' preference for workshops and demonstrations for additional nutrition education, medical education should be reviewed to include compulsory workshop and presentation sections for students to research and present about the national nutrition culture in their home countries. Second, schools should encourage international students to have internships in their respective home countries before graduation. These internships should include time with nutrition and/or public health departments to enable students to learn the nutrition practices of their respective home countries. In addition, clinical rotation for international students in China should include rotation time at the nutrition/dietetics units in the hospitals to provide practice in implementing nutrition in clinical practice. Third, more nutrition professionals such as nutritionists and dieticians should be incorporated into the teaching staff at these medical schools to deliver practical nutrition about specific diseases so students could experience more professional knowledge.

\section{Strengths and weaknesses}

This study has some strengths. To the best of our knowledge, it is the first study to incorporate students from multiple countries from different continents in assessing this all-important issue of nutrition education in medical schools.

Our study also comes with some weaknesses. First, the survey questionnaires were forwarded to various class and school social media platforms for interested students to respond. The various class and school groups that received the survey questionnaires were limited to the ones in which our team members knew at least one student to serve as a lead person. This might be prone to selection bias. Second, the sample size for both homecountry students and international students may not be representative of actual numbers of home-country students and students studying internationally. Third, due to the nature of the survey, responses provided by participants could be considered as subjective depending on participant's understanding of the question at the time and the fact that researchers were not present to provide follow-up questions for clarification.

\section{CONCLUSION}

This cross-sectional survey assessed the nutrition knowledge and factors influencing the capacity of internationally and home-country-trained medical students to offer nutrition guidance. Home-country students were found to rate more highly the significance of nutrition in health and disease development and had greater selfperceived confidence to provide appropriate nutrition advice for specific conditions and disease states compared with internationally trained students. The adequacy of 
nutrition education received at the medical school and the level of confidence in providing nutrition advice to patients correlated with factors including the practical nutrition education received, how often students are asked nutrition-related questions and the hours of teaching in nutrition received. Medical schools in China that train significant numbers of international students need to support these students to become familiar with their respective home countries' nutrition contexts.

Contributors WKA: investigation, formal analysis, writing-original draft, writingreview and editing. SB: investigation, formal analysis, writing-original draft. AF: investigation, formal analysis. MY: conceptualisation, writing-review and editing. JR: conceptualisation, supervision, writing-review and editing, funding acquisition.

Funding The study was supported by the National Key R\&D Program of China (2018YFD0901101), the Guangdong Science and Technology Planning Project (2017B090901063) and the Research and Development Program in Key Areas of Guangdong Province (2019B020210002).

Competing interests None declared.

Patient consent for publication Not required.

Ethics approval The study was approved by the Medical Ethics Committee of the Medical College of the South China University of Technology.

Provenance and peer review Not commissioned; externally peer reviewed.

Data availability statement Data are available upon request through the corresponding author.

Supplemental material This content has been supplied by the author(s). It has not been vetted by BMJ Publishing Group Limited (BMJ) and may not have been peer-reviewed. Any opinions or recommendations discussed are solely those of the author(s) and are not endorsed by BMJ. BMJ disclaims all liability and responsibility arising from any reliance placed on the content. Where the content includes any translated material, BMJ does not warrant the accuracy and reliability of the translations (including but not limited to local regulations, clinical guidelines, terminology, drug names and drug dosages), and is not responsible for any error and/or omissions arising from translation and adaptation or otherwise.

Open access This is an open access article distributed in accordance with the Creative Commons Attribution Non Commercial (CC BY-NC 4.0) license, which permits others to distribute, remix, adapt, build upon this work non-commercially, and license their derivative works on different terms, provided the original work is properly cited, appropriate credit is given, any changes made indicated, and the use is non-commercial. See: http://creativecommons.org/licenses/by-nc/4.0/.

ORCID iD

Jiaoyan Ren http://orcid.org/0000-0002-2063-601X

\section{REFERENCES}

1 Lesourd BM. Nutrition and immunity in the elderly: modification of immune responses with nutritional treatments. Am J Clin Nutr 1997;66:478S-84

2 Micha R, Peñalvo JL, Cudhea F, et al. Association between dietary factors and mortality from heart disease, stroke, and type 2 diabetes in the United States. JAMA 2017;317:912-24.

3 Derbyshire E, Delange J. COVID-19: is there a role for immunonutrition, particularly in the over 65s? BMJ Nutr Prev Health 2020;3:100-5.
4 Russell C, Elia M. Nutrition screening surveys in hospitals in the UK, 2007-2011. Redditch, UK: British Association for Parenteral and Enteral Nutrition, 2014.

5 England PH. Health matters: obesity and the food environment, 2017.

6 Eisenberg DM, Burgess JD. Nutrition education in an era of global obesity and diabetes: thinking outside the box. Acad Med 2015;90:854-60.

7 Organization WH. Children: reducing mortality: fact sheet. Geneva, 2016.

8 Schwartz AK. The effect of a nutrition education program on nutrition knowledge, dietary intake, body composition and perceived sport performance among high school athletes, 2014.

9 HS O, Jang M, Hwang MO, et al. Effect of 1 year e-mail nutrition education after face-to-face encounter at worksite: changes in cardiovascular risk factors. Korean Journal of Nutrition 2009;42:559-66.

10 Ball LE, Hughes RM, Leveritt MD. Nutrition in general practice: role and workforce preparation expectations of medical educators. Aust $J$ Prim Health 2010;16:304-10.

11 Womersley K, Ripullone K. Medical schools should be prioritising nutrition and lifestyle education. BMJ 2017;359:j4861.

12 Martin S, Sturgiss E, Douglas K, et al. Hidden curriculum within nutrition education in medical schools. BMJNPH 2020;3:18-23.

13 Shifler Bowers K, Francis E, Kraschnewski JL. The dual burden of malnutrition in the United States and the role of non-profit organizations. Prev Med Rep 2018;12:294-7.

14 Labadarios D. Malnutrition in the developing world: the triple burden. South African Journal of Clinical Nutrition 2005;18:119-21.

15 Macaninch E, Buckner L, Amin P, et al. Time for nutrition in medical education. BMJ Nutrition, Prevention \& Health 2020;0:1-9.

16 Hargrove EJ, Berryman DE, Yoder JM, et al. Assessment of nutrition knowledge and attitudes in preclinical osteopathic medical students. $J$ Am Osteopath Assoc 2017;117:622-33.

17 Crowley J, Ball L, Hiddink GJ. Nutrition in medical education: a systematic review. Lancet Planet Health 2019;3:e379-89.

18 Ecker O, Nene M. Nutrition policies in developing countries: challenges and highlights, 2012.

19 Chisholm A, Mann K, Peters S, et al. Are medical educators following general medical Council guidelines on obesity education: if not why not? BMC Med Educ 2013:13:53.

20 MOH/GHS. GHA 2013 national nutrition policy, 2013.

21 Mogre V, Stevens FCJ, Aryee PA, et al. Why nutrition education is inadequate in the medical curriculum: a qualitative study of students' perspectives on barriers and strategies. BMC Med Educ 2018;18:26.

22 Kohlmeier M, Nowson CA, DiMaria-Ghalili RA, et al. Nutrition education for the health care professions. J Biomed Educ 2015;2015:1-2.

23 Devries S, Dalen JE, Eisenberg DM, et al. A deficiency of nutrition education in medical training. Am J Med 2014;127:804-6.

24 Vetter ML, Herring SJ, Sood M, et al. What do resident physicians know about nutrition? an evaluation of attitudes, self-perceived proficiency and knowledge. J Am Coll Nutr 2008;27:287-98.

25 Crowley J, Ball L, Han DY, et al. New Zealand medical students have positive attitudes and moderate confidence in providing nutrition care: a cross-sectional survey. Journal of Biomedical Education 2015;2015:1-7.

26 Perlstein R, McCoombe S, Shaw C, et al. Medical students' perceptions regarding the importance of nutritional knowledge and their confidence in providing competent nutrition practice. Public Health 2016;140:27-34.

27 Adams KM, Lindell KC, Kohlmeier M, et al. Status of nutrition education in medical schools. Am J Clin Nutr 2006;83:941S-4.

28 Nestle M, Baron RB. Nutrition in medical education: from counting hours to measuring competence. JAMA Intern Med 2014;174:843-4.

29 Chung M, van Buul VJ, Wilms E, et al. Nutrition education in European medical schools: results of an international survey. Eur $J$ Clin Nutr 2014;68:844-6. 